\title{
Underwater cultural heritage protection in Cyprus and its contribution to Roman archaeology
}

\author{
Mehmetcan Soyluoğlu \\ Independent researcher, mcansoyluoglu@gmail.com
}

\begin{abstract}
The following article focusing on Roman archaeology provides some preliminary results of the Akanthou Underwater Cultural Heritage (UCH) Project, Cyprus. Since 1999, the wider Akanthou project has been identifying, recording, and protecting heritage and seeks to put forward a sustainable management plan for the future preservation of both coastal and underwater sites. The initial 2018 underwater survey led to the addition of further protection measures for the Akanthou coastline, and this paper suggests solutions to different processes affecting the preservation of defined Roman UCH.
\end{abstract}

Key words

Cyprus, Underwater Cultural Heritage, Heritage Protection, Sustainability.

\section{Introduction}

Due to the unique position of Cyprus in the eastern Mediterranean, it has been considered an important landmark, source of trade, and stop-over point since the ancient past. The crucial geopolitical location 
of the island is made evident by the important underwater cultural remains, which are an enormous responsibility for all who are dedicated to the cultural heritage of humanity.

Coastal surveys on the island consistently demonstrate a rich archaeological and historic heritage left by ancient societies and their sea connection (Leonard, 1995; Rautman, 2000; Leidwanger, 2014). The northern coast of the island has been neglected in terms of scientific investigation and identification of cultural heritage. As a result of this, a systematic protection plan for these coastal and wider areas of the island has not yet been completed (see Şevketoğlu et al 2015 for a discussion of issues).

In addition, interest in cultural heritage has grown and become a recreation and tourist attraction in Cyprus and the eastern Mediterranean. While this provides opportunity for funding cultural heritage survey and protection, it can also threaten its preservation (for example see Harpster 2016: 171).

This paper discusses results of a maritime survey project at Akanthou that is providing identification of coastal heritage leading to legal protection. The archaeological landscape is situated on the less known northern coast of the island but it has a long maritime history, according to archaeological evidence (Şevketoğlu, 2006). It is also an increasingly popular tourist site. The aim of this project is to create a sustainable protection plan for coastal archaeological and historical heritage sites and demonstrate their contribution to archaeological knowledge.

\section{Research background and describing the problem}

Akanthou is situated on the northern coast of the island, some $40 \mathrm{~km}$ east of the Kyrenia (Fig. 1), with the earlier archaeological remains dating back to the Aceramic Neolithic period (CyproPPNB/MPPNB) (Şevketoğlu, 2002).

Material evidence from the area shows a strong connection between land and sea. The Neolithic settlement of Akanthou has the highest number of obsidian tool deposits on the island (Şevketoğlu and Hanson, 2015; Moutsiou, 2018), with the sources in Anatolia; this shows ancient and active communication and maritime connectivity between Anatolia and Cyprus. The existence of a variety of fish bones and fishing hooks in the prehistoric settlement also connect prehistoric Akanthou with the sea (Şevketoğlu, 2006).

Even though evidence of continuing occupation is sparce, ancient literary sources suggests that Akanthou was occupied during the Roman period and called Aphrodision. Visible Roman remains along the shoreline (see below) suggest the Roman settlement also had maritime connections. 
Akanthou's maritime connectivity continued through to the 19th-century and are by a carob storehouse. Carob was one of the most traded commodities for 19th- and 20th-century Cyprus. The fruits of the Carob tree (Ceratonia siliqua) were gathered in storehouses positioned on the shore. A sea route connected the storehouses all around the island for export (Orphanos, 1980). Leonard (1995) suggests a correlation between carob storehouses and ancient anchorages due to their geological suitability for anchoring. In order to support his hypothesis, he conducted underwater surveys at Kourion and Nea Paphos, concluding there were modern and ancient maritime networks around Cyprus evidenced by his results and ancient literary sources. The existence of a carob storehouse close to the Roman remains of Akanthou supports the hypothesis of ancient maritime activities at the Roman settlement.

The modern village of Akanthou is becoming a tourist attraction, with new accommodation and some water sports facilities along the ancient shoreline. While new hotel and pier constructions are threatening the underwater cultural heritage, uncontrolled recreational diving activities endanger in situ underwater cultural heritage. In addition to all these factors, local fishing practices, using nets on the sea bed or trawling, can also be seen as a threat for underwater heritage.

\section{Significance and aim of the study}

The scientific investigations on the prehistoric layers of Akanthou-Arkosykos (henceforth Akanthou) have demonstrated a strong connection between sea and the prehistoric settlers (Şevketoğlu, 2006) and led to formal protection of coastal sites. However, a lack of underwater survey prior to 2018 regarding the later periods of the site meant that maritime archaeological protections were limited. Commercial, agricultural and recreational activities around the archaeological settlement of Akanthou risked damaging underwater cultural heritage. For this reason, a sustainable plan involving different stakeholders in the area, such as local villagers, tourists, businesses, and scientists, was required before planning the future growth of the village.

The research project aimed to identify and understand the existing underwater cultural heritage of the Akanthou in order to provide solid grounds for further protection and planning sustainable underwater cultural heritage programmes. The 2018 survey was a first step for further studies on site with the identification process also providing facts on the factors that endanger the site.

From the underwater archaeological viewpoint, the site and in general the northern coast of the island, are poorly represented with archaeological survey data. Lack of data makes island-wide archaeologic interpretation difficult; an issue previously mentioned by some scholars (Jacobsen, 2002) and limits 
the ability to provide evidence to justify protection. The data recorded during this visual survey undoubtedly contributes to knowledge of the island's archaeology and thus provided for its official safeguarding.

\section{Method}

As a first stage of the project, before going to the field, the research started with looking at the ancient sources to gain any possible information about the maritime activities of the site. Following the ancient literature search, in order to understand the site better and gain more information about current maritime practices, some informal interviews were conducted with the local fishers. After archival research and interviews, research carried out in the field. In the field, research methods were noninvasive and visual, consisting of:1. identification; 2. recording; and 3. assessment.

To identify sites, the project team first walked the $4 \mathrm{~km}$ shoreline of Akanthou to observe archaeological and historical features and to identify the possible diving points with potential for ancient maritime activities. Also, the geology of the area was observed and recorded and possible protection problems noted. After the identification of three bays as main diving points, the research team continued the mission under the water.

During the identification process, all historical and natural features connected to the aims of the project were recorded by creating a photographic archive. All registered data entities were stored on a project hard disk in different folders named according to the research area, and the archaeological and historical remains were located on a digital Google Earth map. In this digital map, the underwater survey method (scuba or snorkel), area codes of every diving point (APN, CRB, etc.), borders of the research area, and a colour code for different materials recorded under water were used (brown for pottery, green for metal, etc.). This also created a visual base on which to follow progress and results of the project and assess the results.

Assessment of the identified and recorded data contributed to a report (Şevketoğlu et al., 2018) fulfilling licencing and legal requirements of survey that serves as the first step for sustainable protection and future planning. Under the scope of the Akanthou-Arkosykos project, assessment corresponds to the evaluation of the natural or human-centred problems in the area and their level of danger to the underwater cultural heritage. Briefly, these three processes form a base for a sustainable protection plan for Akanthou. In a broader aspect, also this methodology can be used to develop a structured pipeline for the assessment of endangered underwater cultural heritage. 


\section{Survey areas}

The archive research resulted in detecting two ancient sources that mention the Roman settlement of Aphrodision. Ptolemy’s Geography (Geog. 5.14.1-7) and Strabo's Geography (Geog. 14.6.3) give the name Aphrodision; however, they do not describe the city in great detail and while they both gave some information about anchorages and maritime facilities of other cities there is no mention of Aphrodision in this respect. These two sources do no more than prove the existence of a Roman Aphrodision.

This research focused survey on three bays at Akanthou that demonstrate a potential ancient marine facility close to the current settlement. The site is now in use as a fishing-boat shelter with the addition of a modern breakwater (see Fig. 2). Also, in the same bay, at $1 \mathrm{~m}$ above current sea level, a Roman construction layer was observed (Fig. 3).

Akanthou has one of the biggest carob storehouses on the northern shore of the island, so taking Leonard's suggestion into consideration, part of the project focused on the bay of the 19th-20th-century carob storehouse next to the fishing-boat shelter (Fig. 4).

The third bay at Karaburun provides a protected harbour, and rock cut tombs on top of it's cliffs were observed during the land surveys. For these reasons, underwater survey was also conducted in this bay (Fig. 5).

\section{Results}

Underwater survey results from the three diving points have demonstrated the existing underwater cultural heritage at the shores of Akanthou.

The surveys carried out at the fishing-boat shelter revealed intensive deposits of pottery fragments, mostly belonging to Roman transport amphorae and tablewares (Figs 6, 7, 8). While the transport amphorae are linked with trade, shoreline erosion was also observed so these fragments may have come from the land (Figs 9, 10). The land surveys (see Şevketoğlu and Tuncel, 2011) also demonstrated concentrations of similar pottery types and the remains of the Roman settlement is very close to the shore (Fig. 11). In addition to this, as a result of series of interviews with the local fishers, the team has learned that at deeper points (10 $\mathrm{m}$ and more) some well-preserved amphorae have been caught by the fishing nets and are evidence of maritime trade. 
The major structural finding came from the underwater surveys conducted at the bay of carob warehouse. The base of the carob storehouse pier was observed (Fig. 12). Roman settlement on the land and erosion was also visible, though deposits of other archaeological periods are not visible on the shoreline. A millstone found on the seabed close to the shore strengthens the suggestion that erosion has caused the movement of artefacts from land to sea (Fig. 13).

Compared to the other bays, Karaburun has different characteristics. The bay has a protective geological structure, but there is no easy access by land as the bay is surrounded by vertical, calcareous sandstone slopes. The possibility of a constructed access, the protection it offered small trading ships in difficult weathers, and its proximity to known remains of Aphrodision provided reason to include it in the survey. The survey results were similar to those of the fishing-boat shelter regarding the material culture and erosion with amphorae observed (Fig. 14). The pottery at Karaburun was in better condition than that found in the other bays. This can be linked with human interactions; while the other two research points have regular visitors, who might have collected pottery in good condition, Karaburun is relatively less accessible and therefore maybe have seen less disturbance and so hosts betterpreserved remains.

\section{Discussion}

The survey has shown the presence of extensive material culture under the water and on the shoreline that can be linked with Roman settlement. However, the 2018 survey results suggest that this material has mostly moved from the land rather than representing a primary deposit. The recorded pier by the carob storehouse is in situ and is an excellent example of the industrial heritage of the island.

Regarding protection, while the in situ pier requires formal scale recording and management, material found under water as a secondary deposit raises questions of what to protect and how to protect it. Broken and relocated pottery sherds promise much in terms of providing valuable information about the historical context of the Roman settlement and providing evidence towards the site as a candidate for Aphrodision.

As stated previously, after interviews with the fishers, at deeper depths which were beyond the limits of this research project, several well-preserved amphorae have been reported as found. Initial survey results do not directly illustrate maritime activities, but the presence of transport amphorae would provide important evidence for maritime trade. Interviews suggest more complex underwater cultural heritage remains in the deeper coastal water off Akanthou. 
Several factors endangering archaeological remains were observed during the surveys. One factor observed in all three areas was erosion. The Roman settlement is close to the shoreline and erosion causes great loss, especially for the remains on the slopes where eroded material directly moves to the sea bed and is mixed with underwater deposits. Future protection efforts require recording of erosion deposits to differentiate them from underwater deposits and assessment of how to reduce erosion.

Another observed factor is human-related interactions. The survey results clearly showed that the areas that have more activities have fewer well-preserved archaeological remains. Karaburun may have much better-preserved remains because of less current activity at the bay. The lack of visible archaeological remains around the carob warehouse may be explained by human activities of swimming and scuba diving in the bay removing artefacts.

Fishing is another identified threat for in situ remains on the sea bed, with nets reported as extracting amphorae from their archaeological context.

In order to manage human-related harm to the underwater cultural heritage of Akanthou, strong local involvement, training programmes, public archaeology practices, and communication are necessary to a sustainable protection plan. This can only succeed if the archaeological sites are initially located, defined, and protected.

\section{Conclusion}

This research project successfully reported the archaeological and historical remains at the underwater site of Akanthou leading to official site protection. This is the first stage in establishing a wider sustainable underwater cultural heritage protection plan. Natural and human-based risks were identified with erosion, fishing, and human access to the heritage sites observed during the surveys. The underwater area surveyed was declared a protected monument, extending the shore area protected through previous survey (Şevketoğlu and Hanson, 2015). Undoubtedly, this will lead to a new phase at Akanthou and expansion of the initial survey and the creation of a sustainable protection plan for the area. For the future, more systematic identification and recording activities followed by a more structured protection and maintenance plan for the site are required. This study suggests that the identified problems can only be solved with collaboration and a multi-disciplinary approach and local contribution for a sustainable future of land and underwater cultural heritage (Fig. 15).

From the archaeological perspective, the transport amphorae found, whether from land or sea transportation, provide evidence of Akanthou's active involvement in the island-wide trade network 
and its potential to be the Aphrodision reported in classical literature. The results raise the question again of how goods were transported on the island during the Roman period and provide clues to the existence of ancient maritime facilities. A more focused study for this purpose can be proposed based on promising evidence.

The project has identified and recorded material culture and historical structures in Akanthou. The results help the researchers to gain knowledge about this less known coast of the island. Moreover, the initial underwater survey work helped to protect the cultural heritage of the site and open new pathways for survey and investigations. When all these outcomes are considered, it can be said that this survey fulfilled the aims set out in the funding grant.

\section{Acknowledegments}

I would like to thank the Honor Frost Foundation (HFF) for awarding me with a grant to pursue the 'Underwater Cultural Heritage of Akanthou' project. Without HFF, this work, and many others, would not be possible. The grant allowed the 2018 survey to be undertaken as part of the Akanthou-Arkosykos Rescue Excavation Project, led by the Centre for Archaeology, Cultural Heritage and Conservation, Cyprus International University, directed by Müge Şevketoğlu. The survey would not have been possible without the precious help of all the project team at Akanthou. Thank you to the organization committee and all supporters of MAGS 2020 for supporting my participation. Thanks to their efforts, we as early career researchers found a space to meet, talk, discuss and, more importantly, improve our knowledge of Mediterranean maritime research.

\section{Reference List}

Harpster, M., 2016, Field testing international conventions in Northern Cyprus. The 2009 Karpaz maritime heritage survey. Anatolia 42, 155-178.

Jacobsen W.C., 2002, Regional distribution of transport amphorae in Cyprus in the Late Roman Period, in J. Eiring and J. Lund (ed.), Transport amphorae and trade in the Eastern Mediterranean, 143-148. Aarhus.

Leidwanger, J., 2014, Maritime networks and economic regionalism in the Roman Eastern Mediterranean. Les nouvelles de l'archéologie 135, 32-38. 
Leonard, J., 1995, Evidence for Roman Ports, Harbours and Anchorages in Cyprus, in V. Karageorghis and D. Michaelides (eds), Cyprus and the Sea, 228-246. Nicosia.

Moutsiou, T., 2018, The Obsidian Evidence for Trans-maritime Interactions in the Eastern Mediterranean: The View from Aceramic Neolithic Cyprus. Journal of Mediterranean Archaeology, 31(2), 229-248.

Orphanos, P. I., 1980, Practical aspects of carob cultivation in Cyprus. Portugaliae Acta Biologica, A. XVI. 1-4, 221-228.

Ptolemy, Geography. https://penelope.uchicago.edu/Thayer/E/Gazetteer/Periods/Roman/_Texts/Ptolemy/5/13*.html\#Imag eMapLocation Accessed 13-10-20

Rautman, M., 2000, The busy countryside of late Roman Cyprus, in Report of the Department of Antiquities, 317-331. Cyprus.

Şevketoğlu, M., 2002, Akanthou-Arkosyko (Tatlısu-Ciftlikdüzü) and the Anatolian Connections in the 9th Millennium BCE., in Waldren, W.H., and Enseyat, J.A. (eds), World Islands in Prehistory, International Insular Investigations, V Deia International Conference of Prehistory, 98-106. Oxford.

Şevketoğlu M., 2006, Anatolia and Cyprus relations in the 9th Millenium BC: Akanthou (Tatlisu) rescue Excavation. Anadolu/Anatolia 30, 119-136.

Şevketoğlu, M. and Hanson, I., 2015, Akanthou-Arkosykos, a ninth Millenium BC coastal settlement in Cyprus Environmental Archaeology. The journal of Human Palaeoecology Volume 20.3, 225-238.

Şevketoğlu, M., Hanson, I., Kayacan, N., Ergun, M., Uzdurum, M., Pollak, N., Matsumoto, N., Soyluoğlu, M., Ateş, A M., Yakupoğluları, P., Kalkan, F., İncirlili, M., Gökcan, E and Çetin, N., 2018, Akanthou Rescue Excavation Project and regional Survey Report. Centre for Archaeology, Cultural Heritage and Conservation, Cyprus International University. 
Şevketoğlu, M. and Tuncel, R., 2011, “Tatlisu Bölgesi yuzey arastirmasi Calismalari Raporu NisanAgustoz 2011" Akanthou Region field survey researches, April-August 2011. Centre for Archaeology, Cultural Heritage and Conservation, Cyprus International University.

Şevketoğlu, M., Tuncel, R. and Şahoğlu, V., 2015, Protecting the Cultural Heritage of Cyprus: International Laws and Concerns. Journal of Eastern Mediterranean Archaeology and Heritage Studies (JEMAHS) 3.2, 141-148.

Strabo,Geography. https://penelope.uchicago.edu/Thayer/E/Roman/Texts/Strabo/14F*.htmlAccessed 13-10-20

\section{Figures}

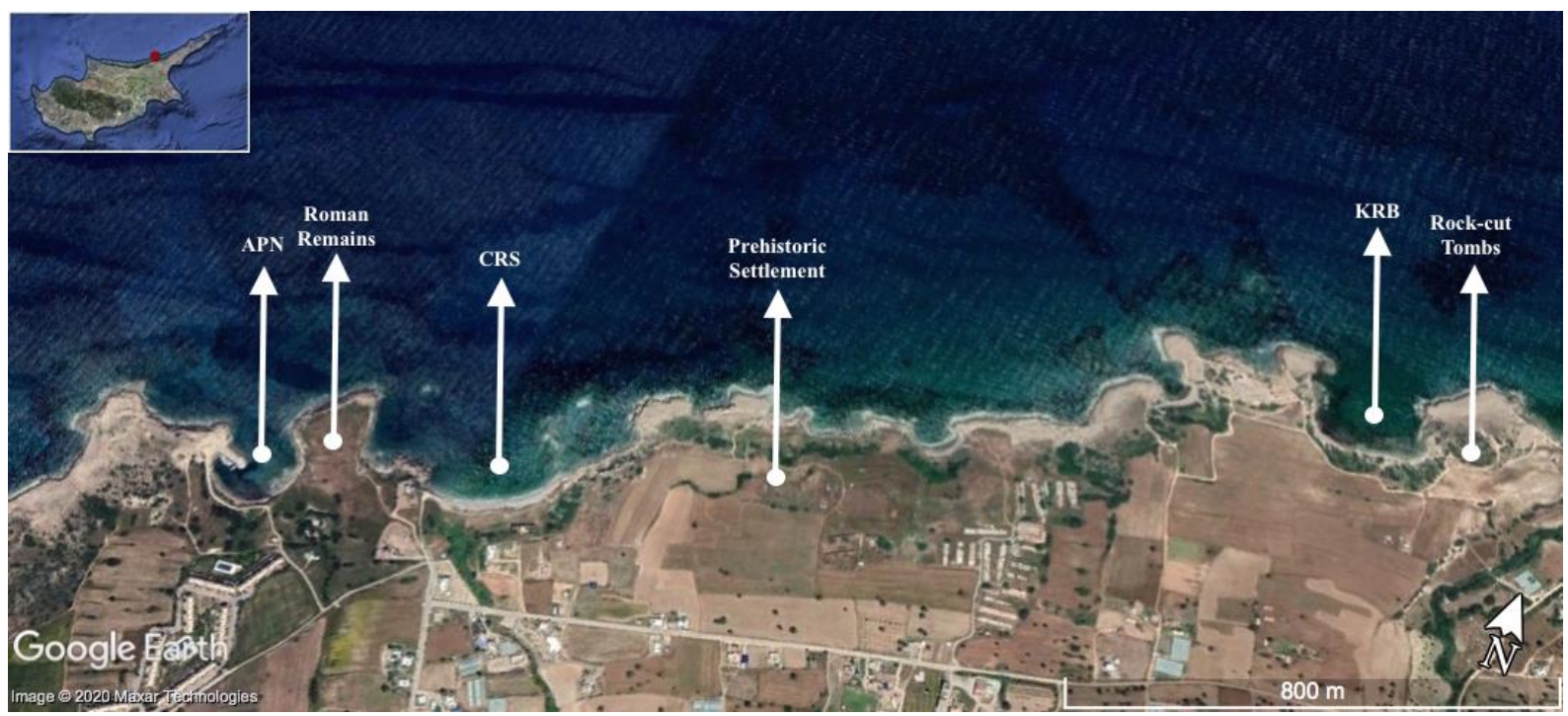

Fig.1 Location of Akanthou-Arkosykos Aceramic Neolithic settlement, in relation with the three surveyed bays. 


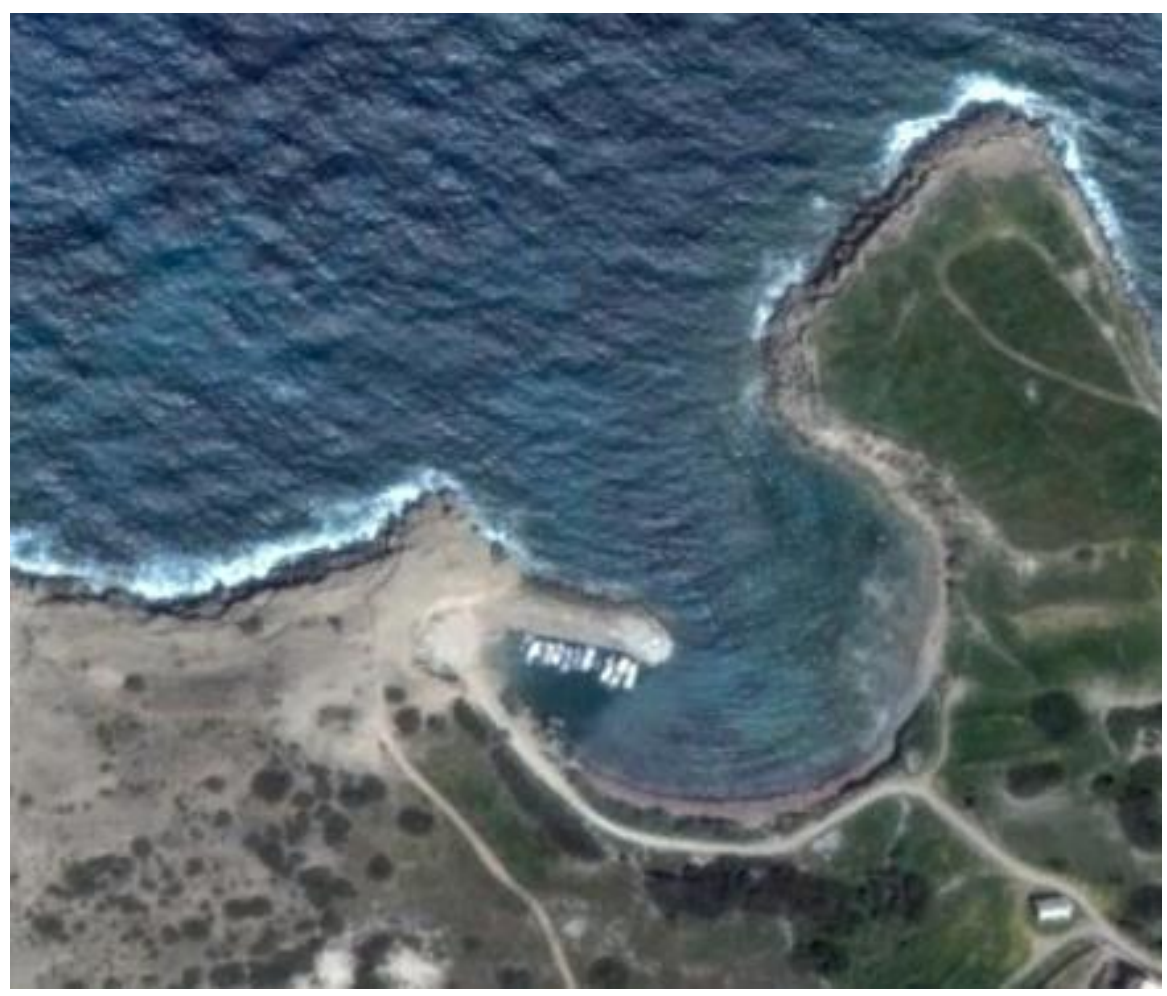

Fig. 2 Satellite photo of fishing-boat shelter

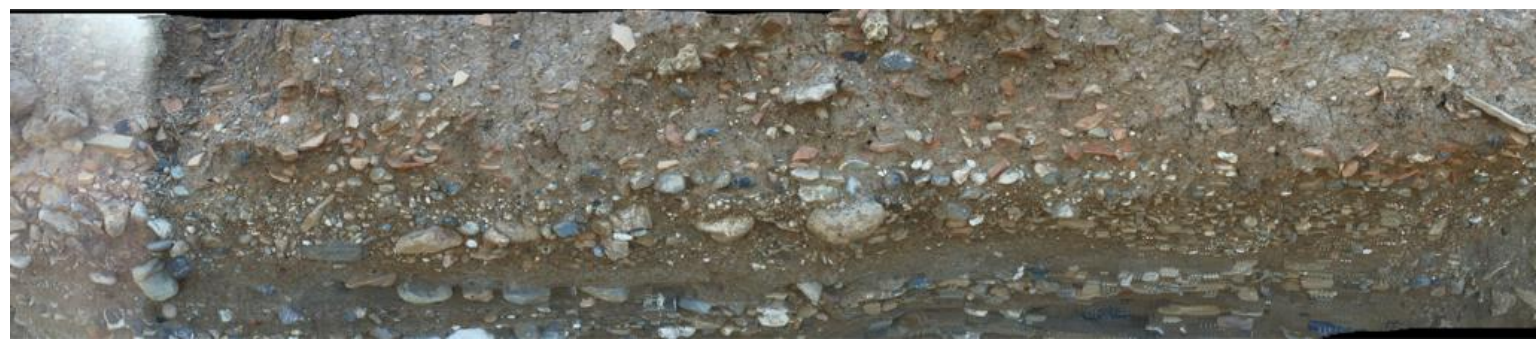

Fig. 3 Roman construction layer $1 \mathrm{~m}$ above sea level at the fishing-boat shelter bay. (Photo taken by Mehmetcan Soyluoğlu) 


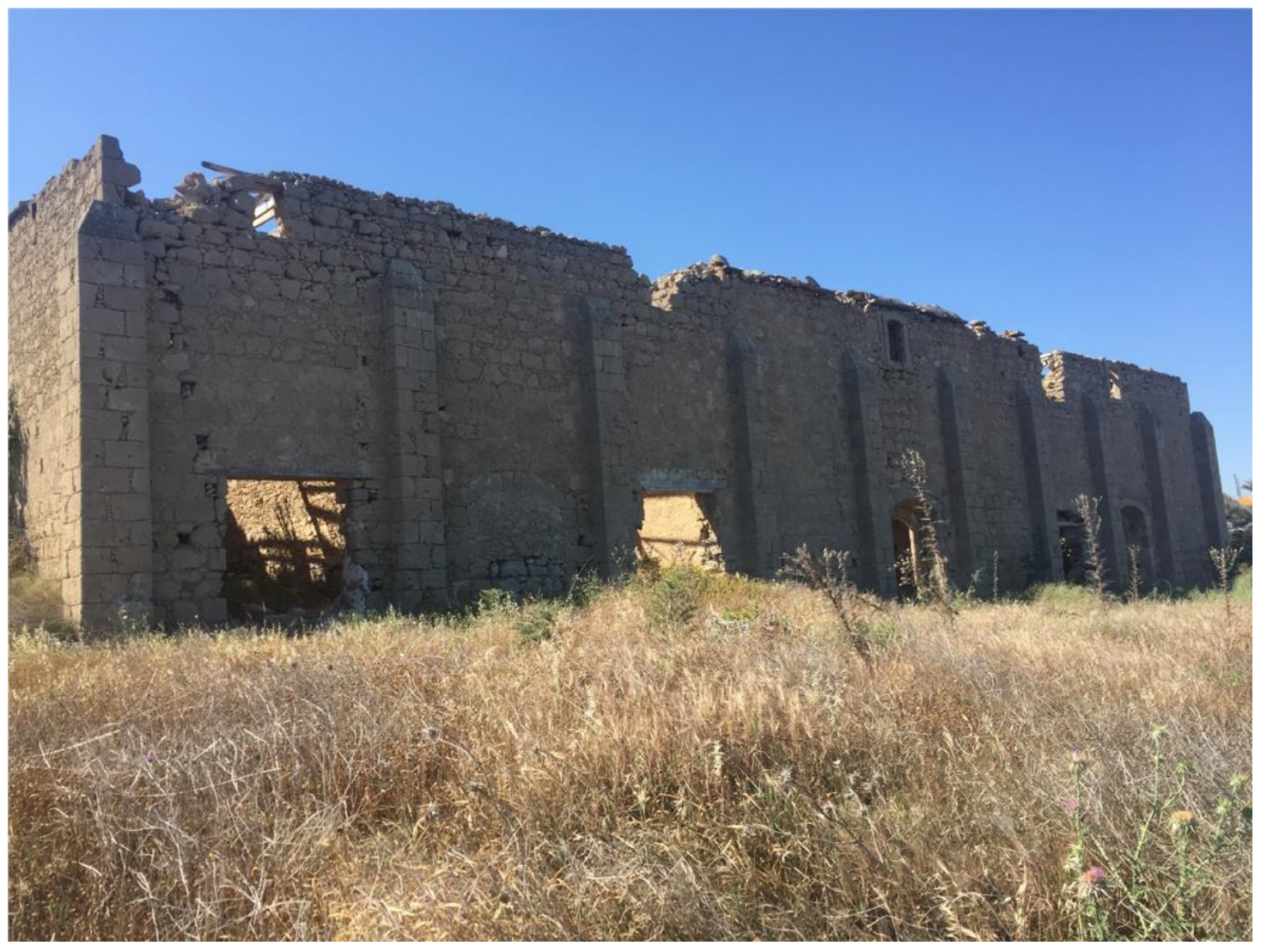

Fig. 4 Carob storehouse (Photo taken by Mehmetcan Soyluoğlu)

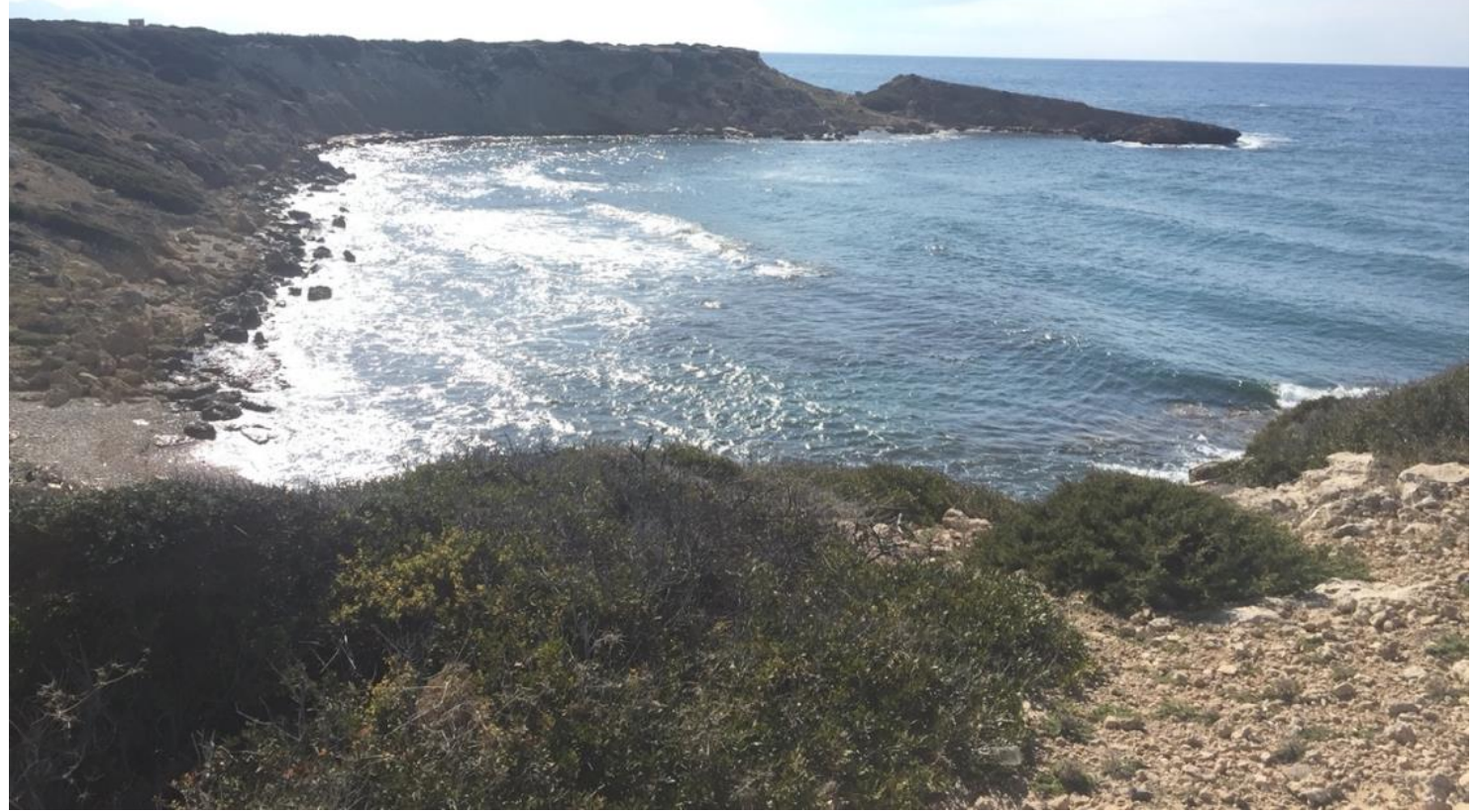

Fig. 5 Karaburun, from the east end of the bay (Photo taken by Mehmetcan Soyluoğlu) 


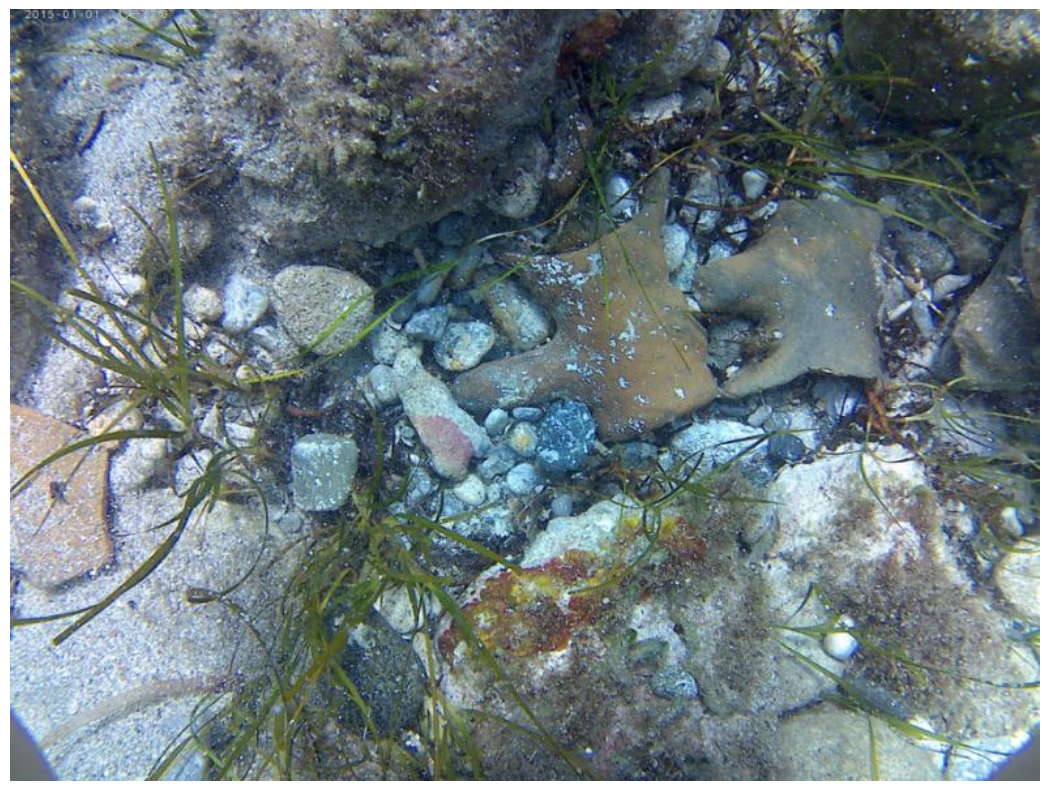

Fig. 6 Pottery fragments from fishing-boat shelter survey (Photo taken by Kemal Ersenal courtesy of Akanthou Project Photo Archive)

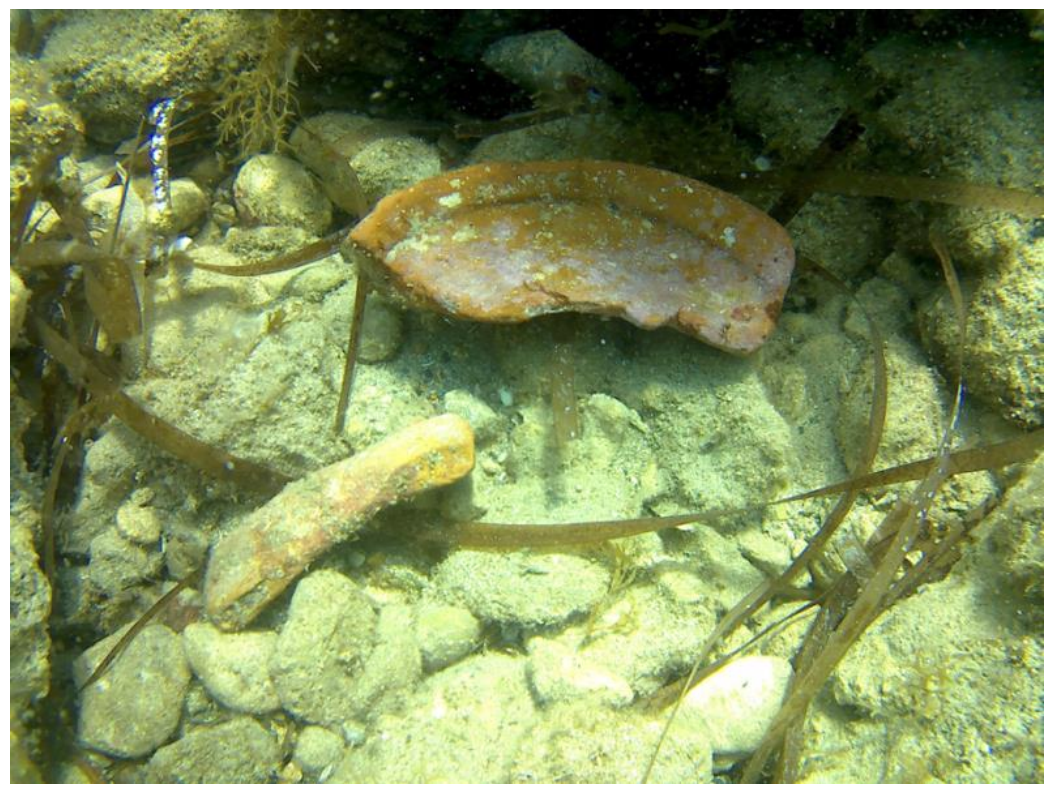

Fig. 7. Pottery fragments from fishing-boat shelter survey (Photo taken by Kemal Ersenal/courtesy of Akanthou Project Photo Archive) 


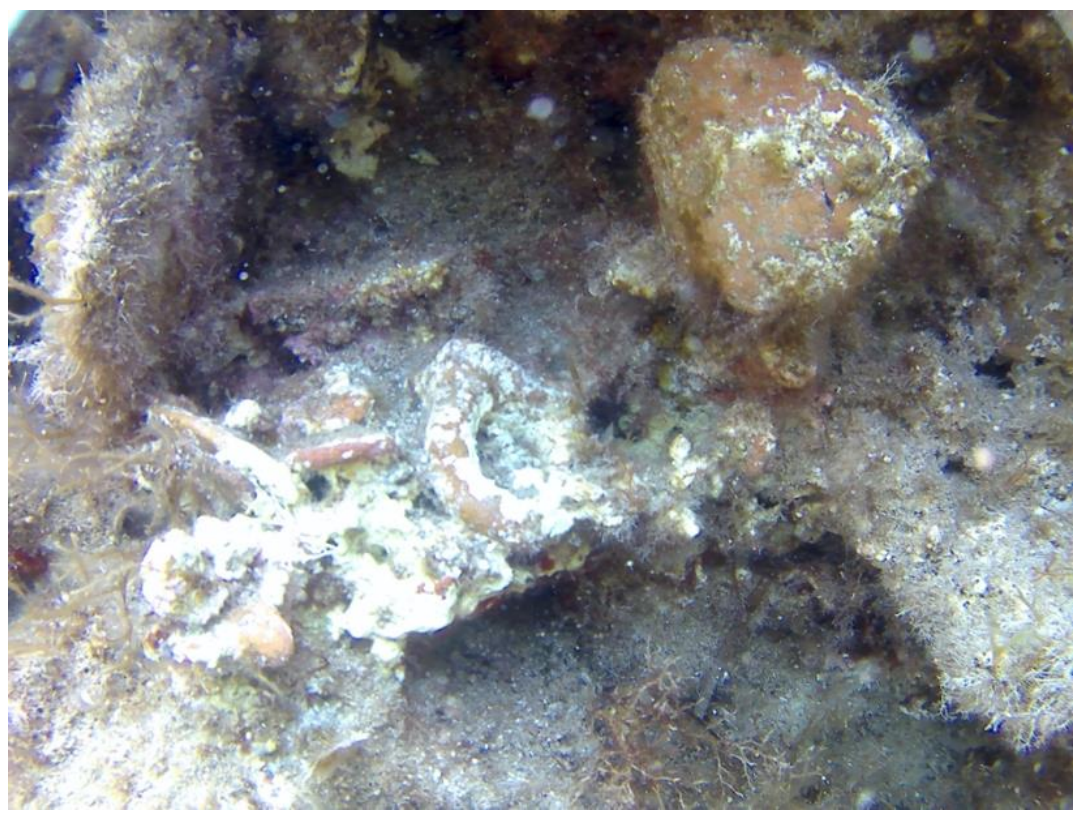

Fig. 8. Pottery fragments from fishing-boat shelter survey (Photo taken by Kemal Ersenal/ courtesy of Akanthou Project Photo Archive)

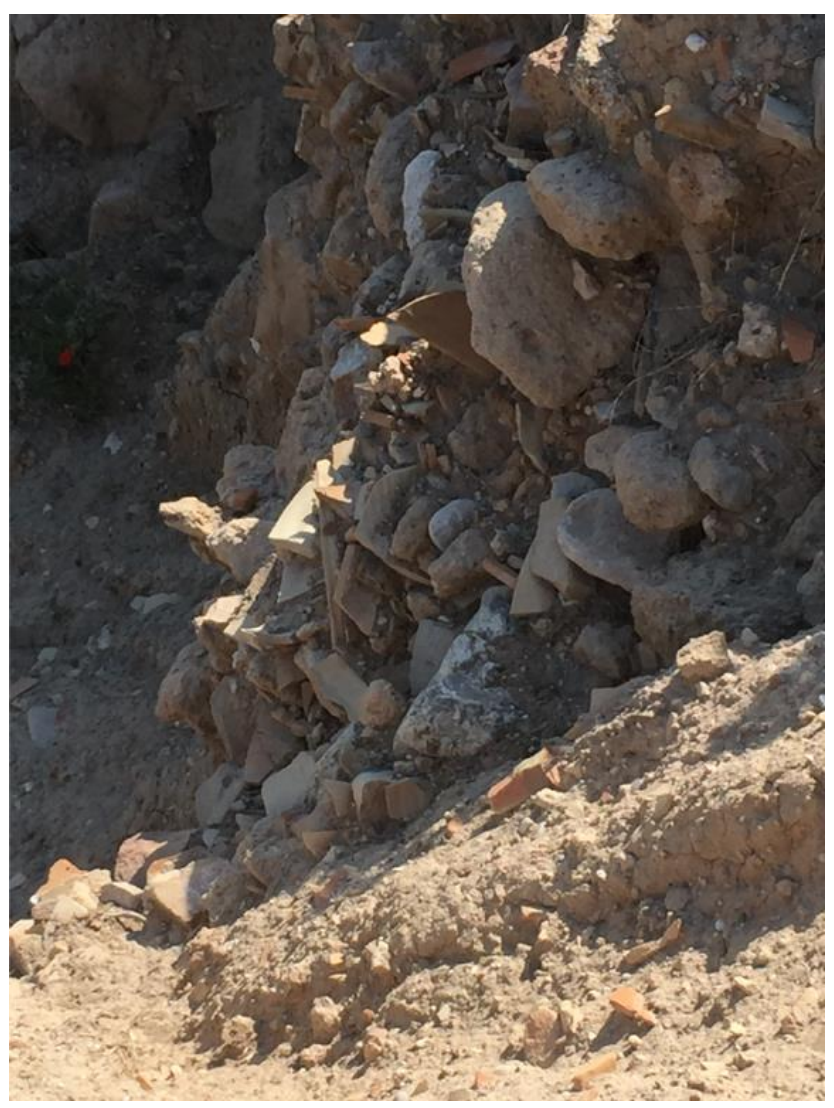

Fig. 9. Erosion from the shore line of Akanthou (Photo taken by Mehmetcan Soyluoğlu) 


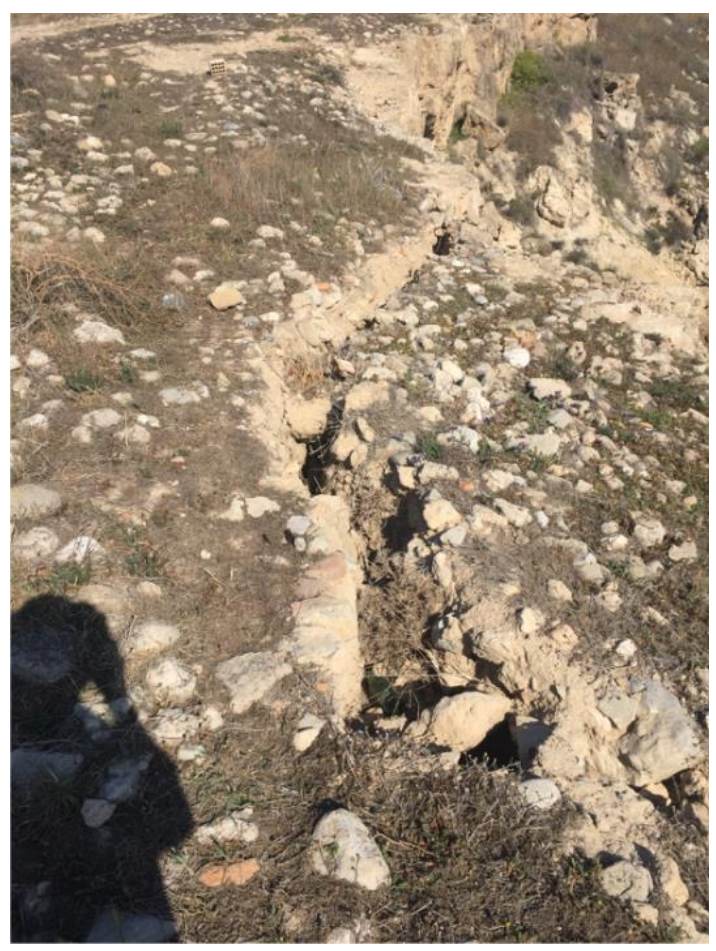

Fig. 10. Erosion from the shore line of Akanthou (Photo taken by Mehmetcan Soyluoğlu)

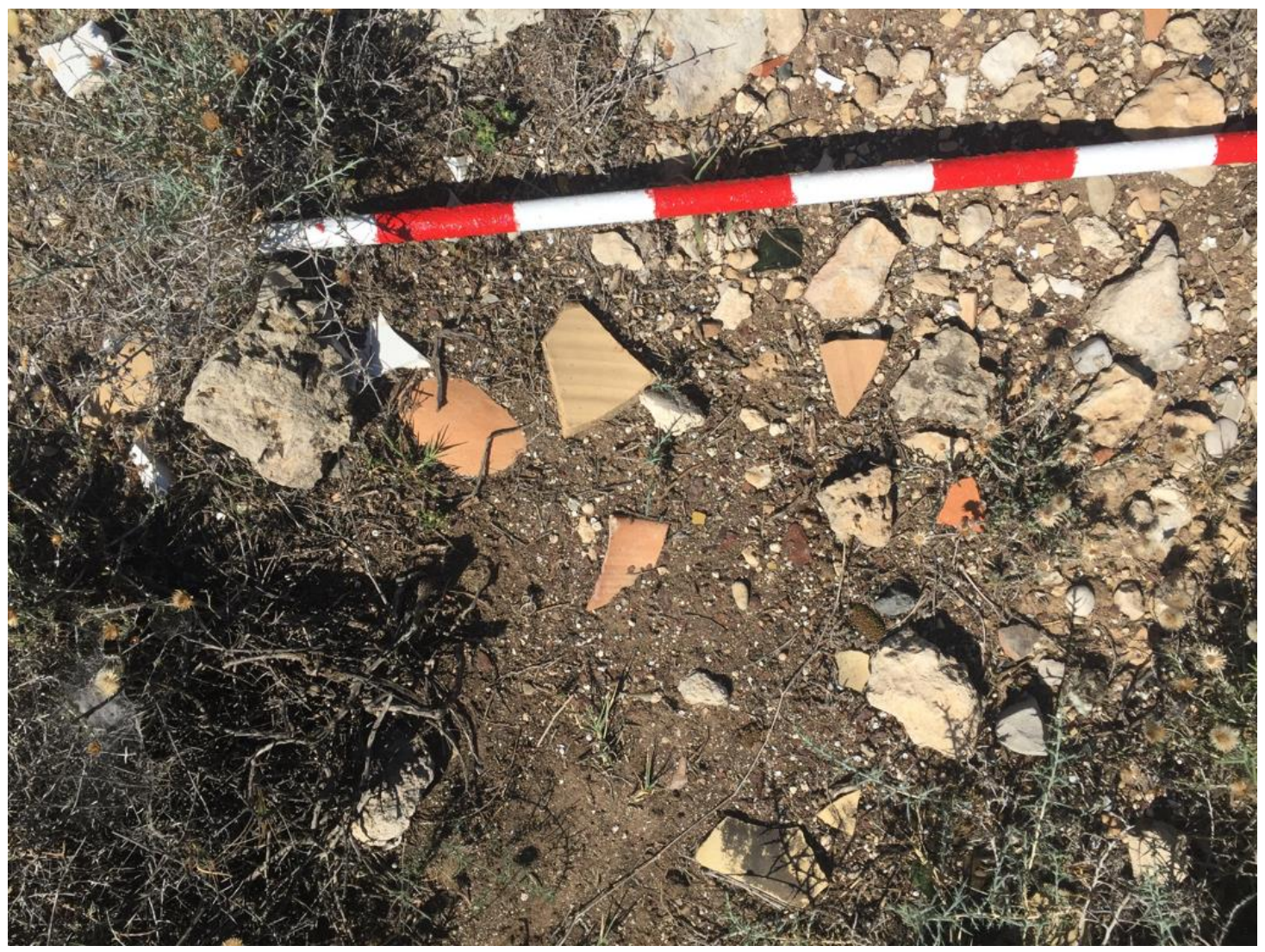

Fig. 11 Pottery sherds from the shore (Photo taken by Mehmetcan Soyluoğlu) 


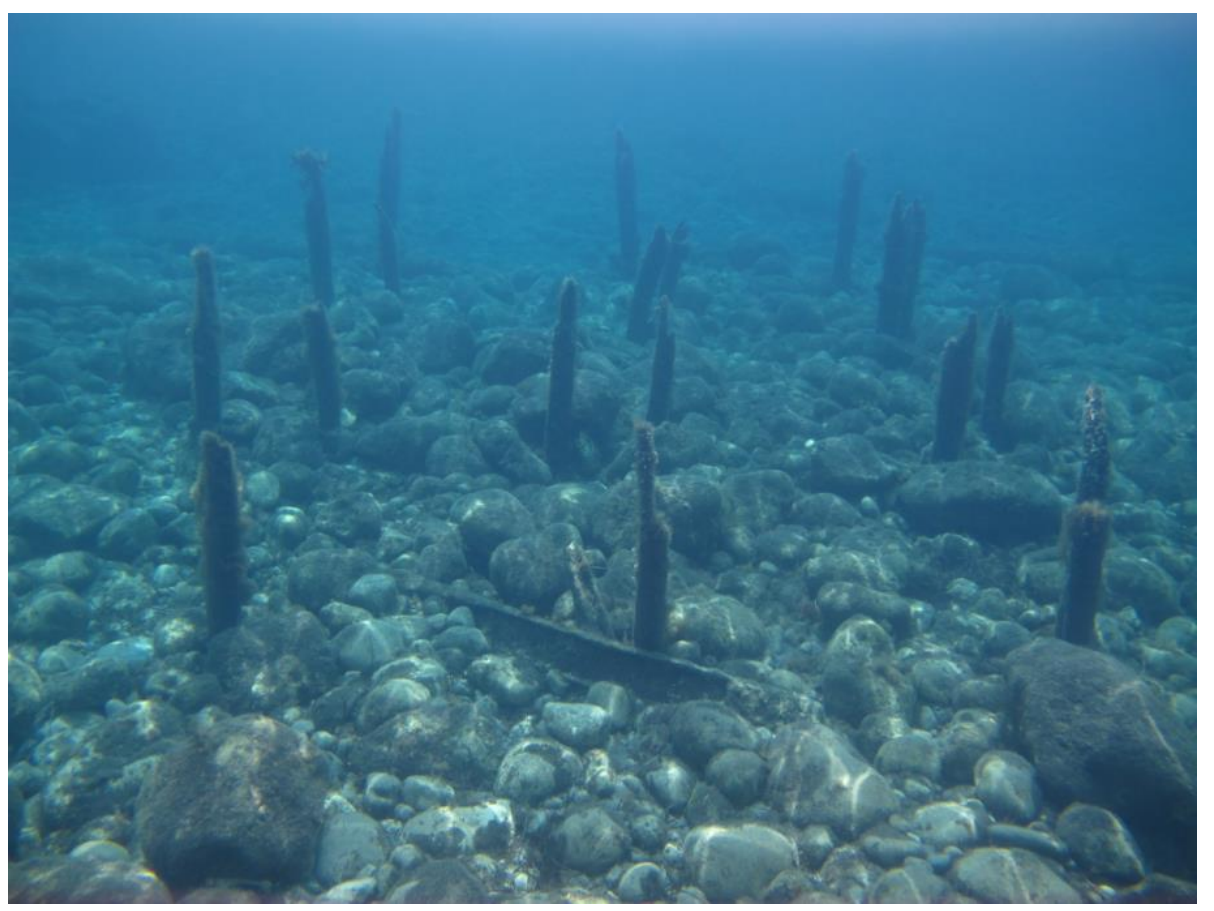

Fig. 12. Carob storehouse pier remains (Photo taken by Kemal Ersenal/ courtesy of Akanthou Project Photo Archive)

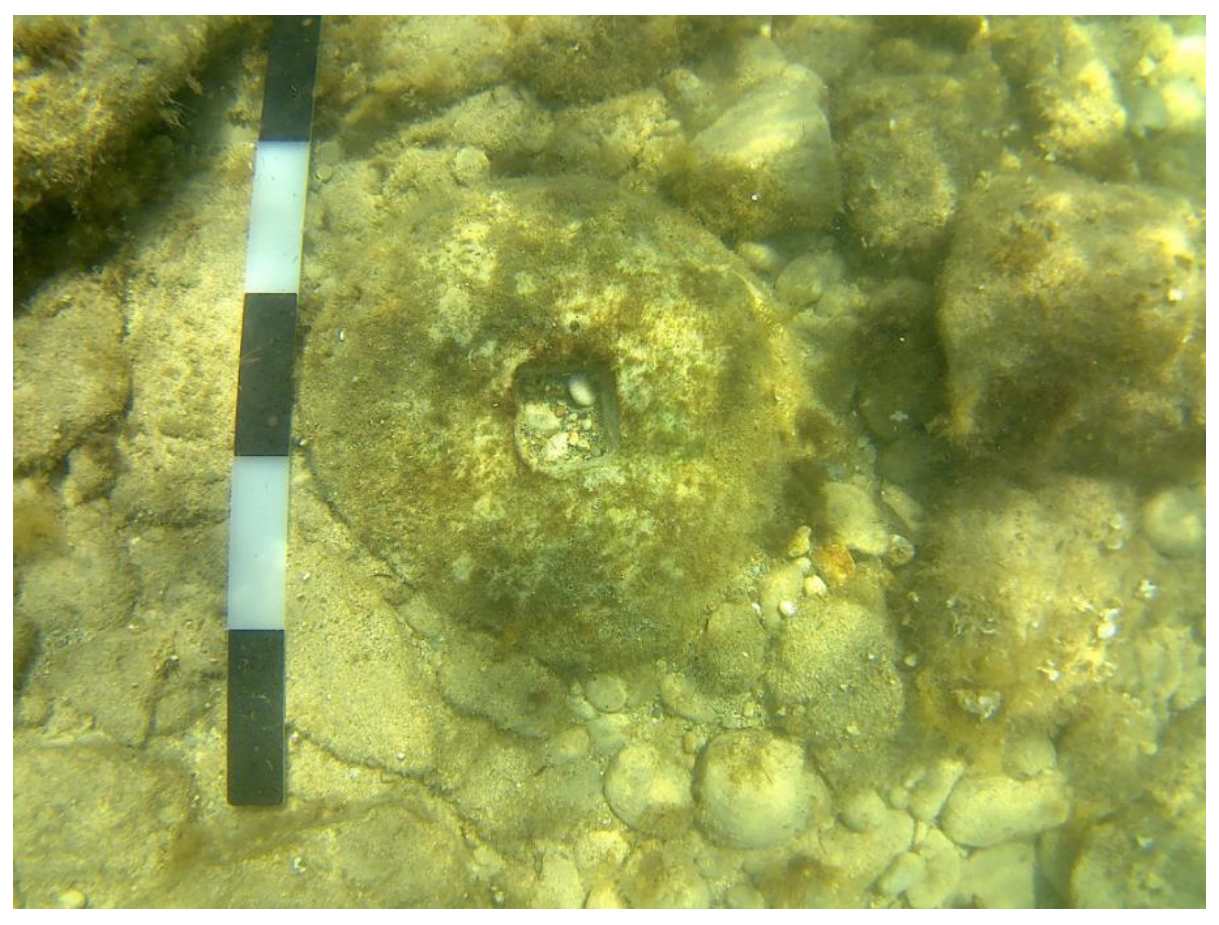

Fig. 13. Mill stone near the carob warehouse (Photo taken by Mehmetcan Soyluoğlu/ courtesy of Akanthou Project Photo Archive) 


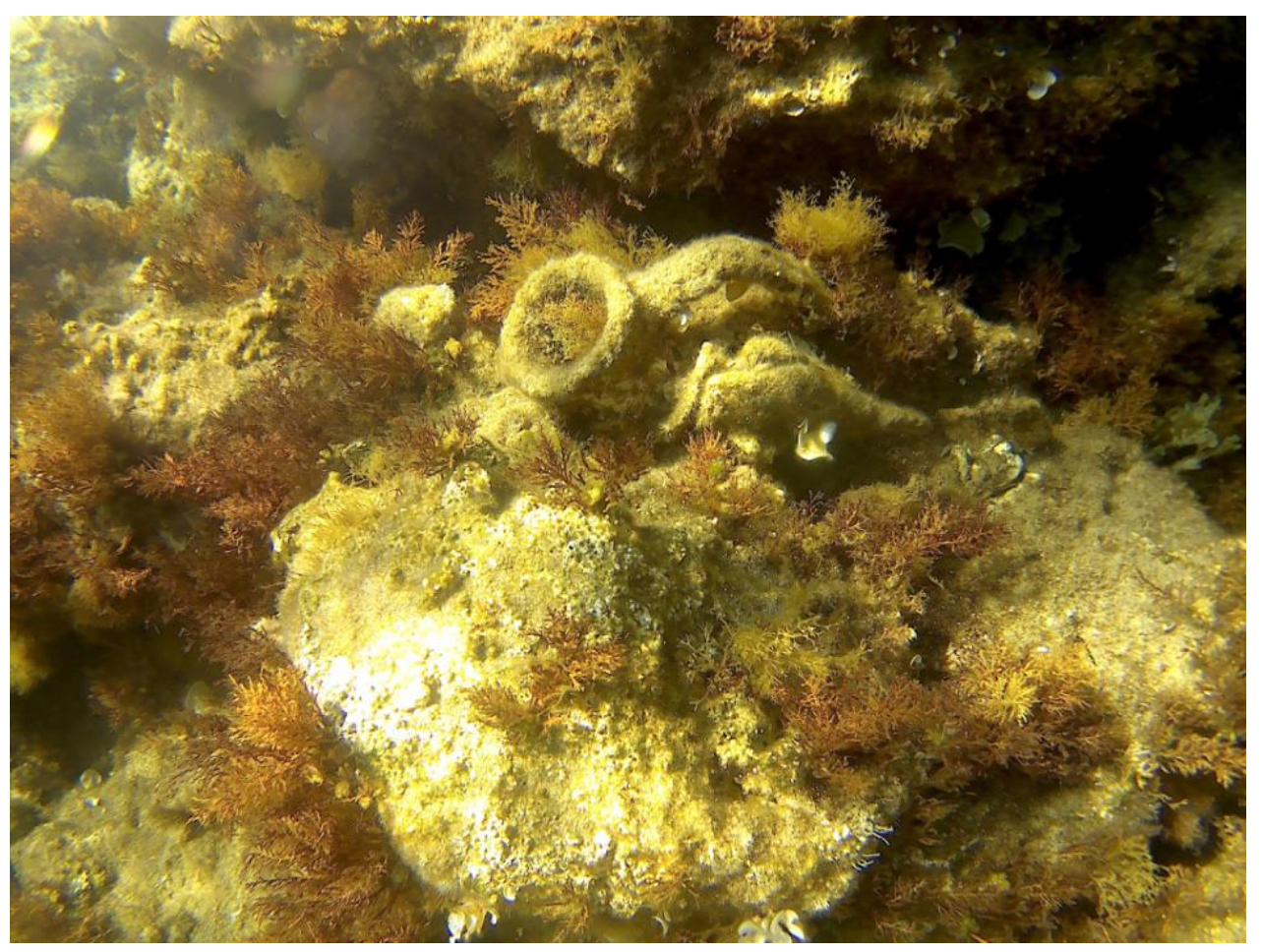

Fig. 14. Pottery remains from Karaburun (Photo taken by Kemal Ersenal/ courtesy of Akanthou Project Photo Archive)

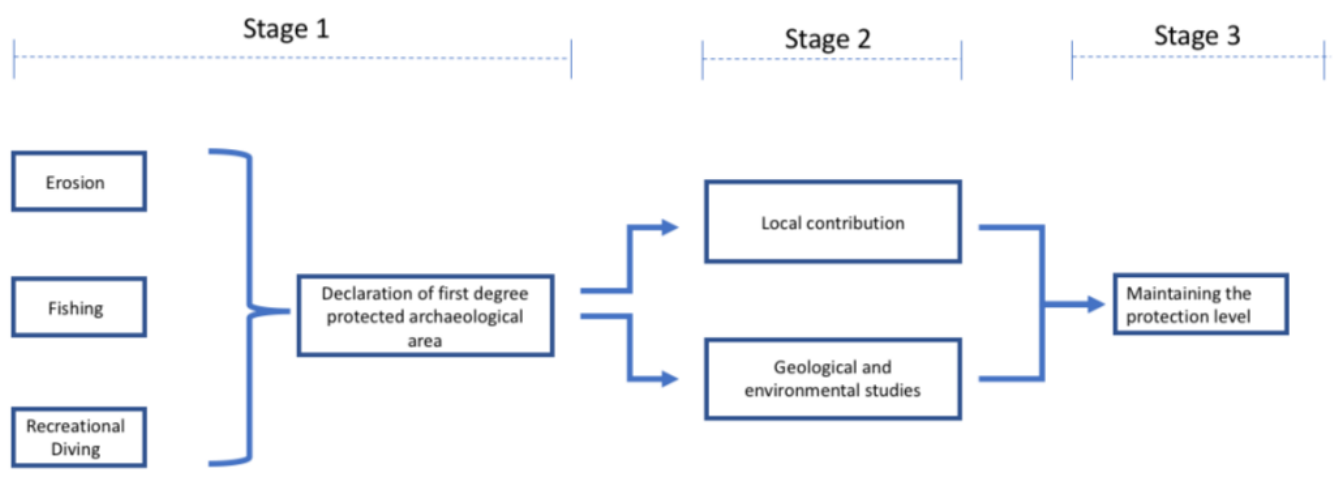

Fig. 15. Schematic representation of detected risk factors and current achievement of the project for preventing current risk factors (stage 1). The future suggestions were also represented at the stage 2 and 3. 